\title{
CORRECTIONS
}

\section{Opioids for chronic non-cancer pain}

A section of the competing interests statement for this Practice paper (BMJ 2013;346:f2937, doi:10.1136/bmj.f2937) was inadvertently deleted during the editing and production stages. The statement should have included the following sentence at the end: "The Anaesthesiology Unit of the University of Western Australia, but not SS personally, has received research and travel funding and speaking and consulting honoraria from Grünenthal, CSL, Janssen Pharmaceuticals, Mundipharma, Pfizer, Phosphagenics, and iX Biopharma within the last five years."

Cite this as: BMJ 2014;349:g4641

๑) BMJ Publishing Group Ltd 2014 